\title{
Ação antrópica em torno das nascentes da Microbacia do Rio Bitury, Município de Belo Jardim (Região Agreste de Pernambuco)
}

\section{Luciano Gomes da Silva Júnior}

Autarquia Educacional de Belo Jardim. Departamento de Ciências Biológicas. Rodovia PE-166, km 05. Sítio Inhumas. Belo Jardim-PE (CEP 55150-000). E-mail: lucgomesjr@gmail.com.

Resumo. Os impactos ambientais numa bacia hidrográfica revestemse de maior importância por afetarem um dos principais recursos naturais necessário à vida. Existem diversos fatores que podem alterar a quantidade e a qualidade da água das nascentes de uma bacia hidrográfica, compreendendo os fatores naturais e os que são resultantes da ação antrópica. A Microbacia do Rio Bitury está inserida na Bacia Hidrográfica do Rio Ipojuca, na Região Agreste do Estado de Pernambuco, no Município de Belo Jardim, em uma área de Brejos de Altitude, contendo inúmeras nascentes, fornecendo água para consumo humano, atividades agropecuárias e industriais, tendo importância relevante para a região. Nesse contexto, o objetivo deste trabalho foi quantificar o impacto humano sobre a vegetação ciliar de 66 nascentes encontradas na microbacia. Foram testadas hipóteses referentes ao impacto que a população humana exerce sobre a qualidade da mata do entorno das nascentes avaliado por meio do Índice da Vegetação por Diferença Normalizada (NDVI). Foram localizadas 66 nascentes e definidas 50 áreas controle, que tiveram suas coordenadas geográficas definidas utilizando-se um aparelho de GPS (Garmim, Colorado 300). Foi usado o programa ArcGis 9.2 para criar áreas com um raio de $50 \mathrm{~m}$, tanto nas áreas controle como nas nascentes, conforme a determinação do Conselho Nacional do Meio Ambiente (CONAMA). As nascentes apresentaram valores de NDVI diferentes entre si e, em média $(0,57 \pm 0,082)$, significativamente $\left(\mathrm{F}_{1 / 982}=189,91 ; \mathrm{p}<0,001\right)$ menores do que o NDVI médio das áreas controle $(063 \pm 0,036$; média \pm DP). Portanto, foi observado que o estado de conservação das nascentes é significativamente pior do que das áreas controle, mesmo que em alguns casos as nascentes possam apresentar certo grau de cobertura vegetal, indicando assim, um processo antrópico de degradação numa área de preservação permanente, com possíveis repercussões na disponibilidade e qualidade hídrica na região. A avaliação das interações dos recursos e das ações antrópicas, diagnosticando as condições das nascentes, se faz necessário para orientar as possíveis intervenções.

Palavras-chave: Nascentes, Antropismo, Microbacia.

Abstract. Antropic action around the headwaters of the Watershed of the Bitury River, Municipality of Belo Jardim (Agreste Region of Pernambuco). Environmental impacts in a river basin are of utmost importance to affect one of the main natural resources necessary for

Recebido: 18/06/2015

Aceito: 25/12/2015

Publicado: 31/12/2015

Acesso Aberto

Artigo completo

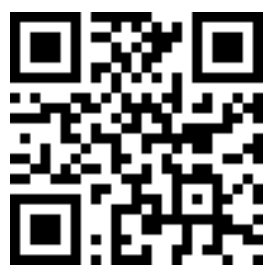


life. There are several factors that modify the quantity and quality of spring water from one river basin, comprising the environmental factores and those resulting from human activities. The watershed Bitury is within the catchment area of River Ipojuca Basin, in the Agreste Region of the State of Pernambuco, in the Municipality of Belo Jardim, in an area of swamps altitude, containing several springs providing water for human consumption, agricultural and industrial activities, and importance for the region. In this context, the aim of this study was to quantify the human impact on the riparian vegetation of 66 springs found in the watershed. Hypotheses were tested for the impact that the human population has on the surrounding woods of the quality of sources assessed by the Normalized Difference Vegetation Index (NDVI). Sources were located 66 and 50 defined control areas which had their geographical coordinates determined using a GPS device (GARMIN, Colorado 300). The ArcGIS 9.2 software was used to create areas with a radius of $50 \mathrm{~m}$, both in the areas control as in the springs as the determination of the National Environmental Council (CONAMA). The springs had different NDVI values with each other and averaged $(0.57 \pm 0.082)$, significantly $\left(\mathrm{F}_{1 / 982}=189.91, \mathrm{p}<0.001\right)$ lower than the average NDVI of control areas $(063 \pm 0.036$, mean \pm SD). So it was observed that the nascent conservation status is significantly worse than the control areas, even though in some cases the sources can provide some degree of vegetation cover, thus indicating an anthropic degradation process in a permanent preservation area, with possible impact on the availability and water quality in the region. The evaluation of interactions of resources and human activities, diagnosing the condition of springs, it is necessary to guide possible interventions.

Keywords: Headwaters, Anthropism, Watershed.

\section{Introdução}

A crescente preocupação com a escassez de água potável é bastante justificável, pois se sabe que a forma como esse recurso natural tem sido utilizado ameaça o desenvolvimento do ser humano e a proteção do ambiente (Hermani, 1997). Para Xavier e Teixeira (2007) a exploração inadequada dos recursos naturais de forma cada vez mais desordenada, através de atividades de desmatamentos, práticas agrícolas perniciosas, atividades extrativistas agressivas, a construção indiscriminada de barramentos, o lançamento de esgotos industriais e domésticos nos rios e lagos, promovem inúmeros problemas ambientais, principalmente em matas ciliares e áreas de nascentes.

Oliveira-Filho et al. (1994) e

Donadio et al. (2005), afirmam que a devastação das matas ciliares tem contribuído para o assoreamento, o aumento da turbidez das águas, o desequilíbrio do regime das cheias, a erosão das margens de grande número de cursos d'água, além do comprometimento da fauna silvestre. Arcova e Cicco (1997) salientam que, nas microbacias de uso agrícola, quando comparadas às de uso florestal, o transporte de sedimentos e a perda de nutrientes são maiores. Diversos estudos sobre a qualidade da água em microbacias têm sido realizados, enfocando a importância da conservação dos recursos naturais desses ambientes de modo a garantir a disponibilidade de água de boa qualidade (Pineda e Schafer, 1987; Arcova e Cicco, 1999; Souza e Tundisi, 2000; Primavesi et al., 2002).

As nascentes são de extrema importância para os demais corpos d’água 
da microbacia. A água oriunda de uma nascente formará um pequeno córrego que irá contribuir para o volume de água de outro curso e, assim, sucessivamente, até alcançar o mar. Portanto, o desaparecimento de uma nascente resultará na redução do número de cursos d'água, significando a diminuição da disponibilidade de água doce para os diversos usos (Castro, 2001).

A conservação das nascentes está na dependência vital da manutenção da cobertura vegetal no seu entorno, como concluíram Donadio et al. (2005) em estudo realizado com o objetivo de verificar a influência de remanescentes de vegetação ciliar e da ação antrópica na qualidade da água de nascentes, concluindo que a presença de remanescentes de vegetação de mata ciliar auxilia na proteção desses mananciais. O sistema de nascentes é constituído pela vegetação, solo, rochas e relevo das áreas adjacentes e à montante das nascentes e sua preservação é fundamental para manter a qualidade dos recursos hídricos (Souza et al., 2006).

Philippi Jr. e Silveira (2005), ao considerarem a complexidade progressiva dos recursos hídricos nos aspectos natural e antrópico, desde a nascente até o mar, afirmam que a complexidade é ampliada quando somada às transformações promovidas pelas atividades antrópicas nas suas variadas formas de apropriação dos recursos naturais. Torna-se patente que 0 antropismo é o principal fator de degradação do ambiente e principalmente em ambientes frágeis.

A caracterização do meio físico das nascentes e sua área de preservação são condições básicas para a conservação e o uso racional da água. Neste sentido, existem várias leis, decretos e resoluções que regulamentam o uso dos recursos hídricos. $\mathrm{O}$ Código das Águas (Decreto $\mathrm{n}^{\circ}$ 24.463/1934) (Brasil, 1934), colocava como competência do Ministério da Agricultura a administração dos recursos hídricos, refletindo o enfoque agrário na gestão desses recursos; a Lei ${ }^{\circ}$ 9.433/1997 (Brasil, 1997) que deu grande impulso ao gerenciamento dos recursos hídricos, quando instituiu a Política Nacional de Recursos Hídricos (PNRH) e definiu como um de seus instrumentos o enquadramento dos corpos d'água em classes segundo os usos preponderantes. A classificação das águas, a nível nacional, foi estabelecida pela Resolução CONAMA n ${ }^{\circ}$ 20/1986 (Brasil, 1986) atualizada pela Resolução $n^{\circ}$ 357/2005 (Brasil, 2005). A Lei $n^{\circ}$ 4.771/1965 (Brasil, 1965), que reformulou o Código Florestal de 1934 (Brasil, 1934), posteriormente revogada pelo novíssimo código florestal (Lei $\mathrm{n}^{\circ}$ 12.651/2012), (Brasil, 2012) estabeleceu em seu texto a preservação permanente das áreas situadas nas margens das nascentes. A Resolução CONAMA $n^{\circ}$ 04/1985 (Brasil, 1985), substituída pela Resolução $n^{\circ}$ 303/2002 (Brasil, 2002), regulamenta as áreas de nascentes ou olhos d'água como de preservação permanente.

Segundo o Conselho Nacional do Meio Ambiente (CONAMA) e o Código Florestal (Lei $\mathrm{n}^{\circ}$ 12.651/2012) (Brasil, 2012), em nascentes (mesmo intermitentes) e olhos d'água, a distância a ser preservada é de $50 \mathrm{~m}$. No entanto, o que se observa muitas vezes é que as atividades humanas não respeitam essa medida.

A Microbacia do Rio Bitury, localizada no município de Belo Jardim, integrante da Bacia Hidrográfica do Rio Ipojuca, constitui um cenário perfeito para um estudo envolvendo a ação antrópica sobre a qualidade da água e a repercussão sobre a saúde humana. Esta microbacia é de grande importância para o Agreste de Pernambuco, fornecendo água tanto para o consumo humano, quanto para o uso na agropecuária e na indústria, oriunda das suas nascentes e acumulada no Açude Engenheiro Severino Guerra, conhecido como Açude Bitury, constituindo-se em importante alternativa para o desenvolvimento socioeconômico da região.

Diante do exposto, o objetivo desse estudo foi avaliar os impactos causados pela ação antrópica no entorno das nascentes da Microbacia do Rio Bitury, e as transformações do meio ambiente que interferem na saúde ambiental, produzindo repercussões significativas à saúde humana. Foram testadas as hipóteses de que (1) existe diferença significativa na qualidade da mata em torno das 66 nascentes da microbacia; 
(2) existe correlação entre a qualidade das nascentes e a distância (a) do açude principal da bacia, e (b) da sede do município; e (3) existe correlação negativa entre uso humano das nascentes e qualidade da vegetação em torno.

\section{Material e Métodos}

\section{Área de estudo}

$\mathrm{O}$ estudo foi realizado na Microbacia do Rio Bitury, parte integrante da Bacia Hidrográfica do Rio Ipojuca, no Município de Belo Jardim, na Região Agreste Central de Pernambuco (Figura 1). A área é recortada por rios perenes, porém de pequena vazão e o potencial de água subterrânea é baixo. O clima é do tipo tropical chuvoso, com verão seco (Brasil, 2005).

Esta microbacia drena uma área de aproximada de $6.876 \mathrm{ha}$, com um grande número de nascentes e corpos d'água; tem sua água acumulada no Açude Engenheiro Severino Guerra, também conhecido como Açude Bitury (Figura 2), acumulando um volume de 17.776.470 $\mathrm{m}^{3}$ de água (SRHPE, 2010), abastecendo os Municípios de Cachoeirinha, Tacaimbó, São Bento do Una e Belo Jardim, bem como reforça o abastecimento dos Municípios de Pesqueira e Sanharó.

O Programa Nacional do Meio Ambiente II, juntamente com a Secretaria de Tecnologia e Meio Ambiente de Pernambuco (SECTMA) em parceria com a ONG Consubitury (Conselho dos Usuários do Bitury), contemplou a Microbacia do Rio Bitury no Projeto Proteção e Conservação Ambiental da Bacia do Rio Ipojuca, com o objetivo de recuperar e preservar suas nascentes. Para execução do referido projeto foram obtidas as coordenadas geográficas de 148 nascentes, utilizando um receptor GPS, cadastradas 26 propriedades e 35 nascentes e os dados do cadastramento geraram um conjunto de informações constituindo um banco de dados para futuras consultas.

Das nascentes catalogadas, foram selecionadas, para este estudo, 66 que apresentavam distância suficiente entre si para que não formasse sobreposição da área estimada pela legislação, que estabelece um raio de $50 \mathrm{~m}$ de margem, critério que foi utilizado neste trabalho.

Nas observações realizadas em campo, verificou-se que as nascentes que estão localizadas muito próximas entre si apresentam condições semelhantes de cobertura vegetal.

\section{Análise da cobertura vegetal no entorno das nascentes \\ Os sistemas de informações} geográficas podem ser considerados como uma ferramenta muito importante na identificação e avaliação de áreas ocupadas por propriedades de diferentes portes e pela vegetação natural, além do monitoramento anual do desflorestamento em certas regiões (Assad, 1998; Shimabukuro et al., 1998; Loch e Kirchiner, 2000; Reis et al., 2004).

O NDVI (Normalized Difference Vegetation Index) é um importante indicador do estado de cobertura vegetal da superfície e pode contribuir na identificação de áreas que se apresentam florestadas como as que estão degradadas. Este índice de vegetação é baseado em uma combinação aritmética que focaliza o contraste entre os modelos de respostas da vegetação nas faixas do vermelho visível e do infravermelho próximo. A reflectância da cobertura vegetal na banda vermelha visível é baixa, aparecendo nas imagens em tons de cinza escuros, devido à absorção da clorofila existente nas folhas. Entretanto, no infravermelho próximo apresenta alta reflectância com tons de cinza claro devido à dispersão causada pela estrutura das folhas (Lillesand e Kiefer, 1994), o qual consiste em uma equação que tem como variáveis as bandas do vermelho visível e infravermelho próximo, como apresentada a seguir:

$$
\begin{aligned}
& \text { NDVI = (IVP - V) / (IVP + V) } \\
& \text { Onde: } \\
& \text { IVP = valor da refletância da banda no } \\
& \text { infravermelho próximo; } \\
& \text { V = valor de refletância da banda no } \\
& \text { vermelho visível. Seus valores variam } \\
& \text { entre - } 1 \text { e }+1 \text {; superfícies verdes têm } \\
& \text { um NDVI entre } 0 \text { e } 1 \text { e a água e nuvens } \\
& \text { tem geralmente NDVI menor que zero. }
\end{aligned}
$$




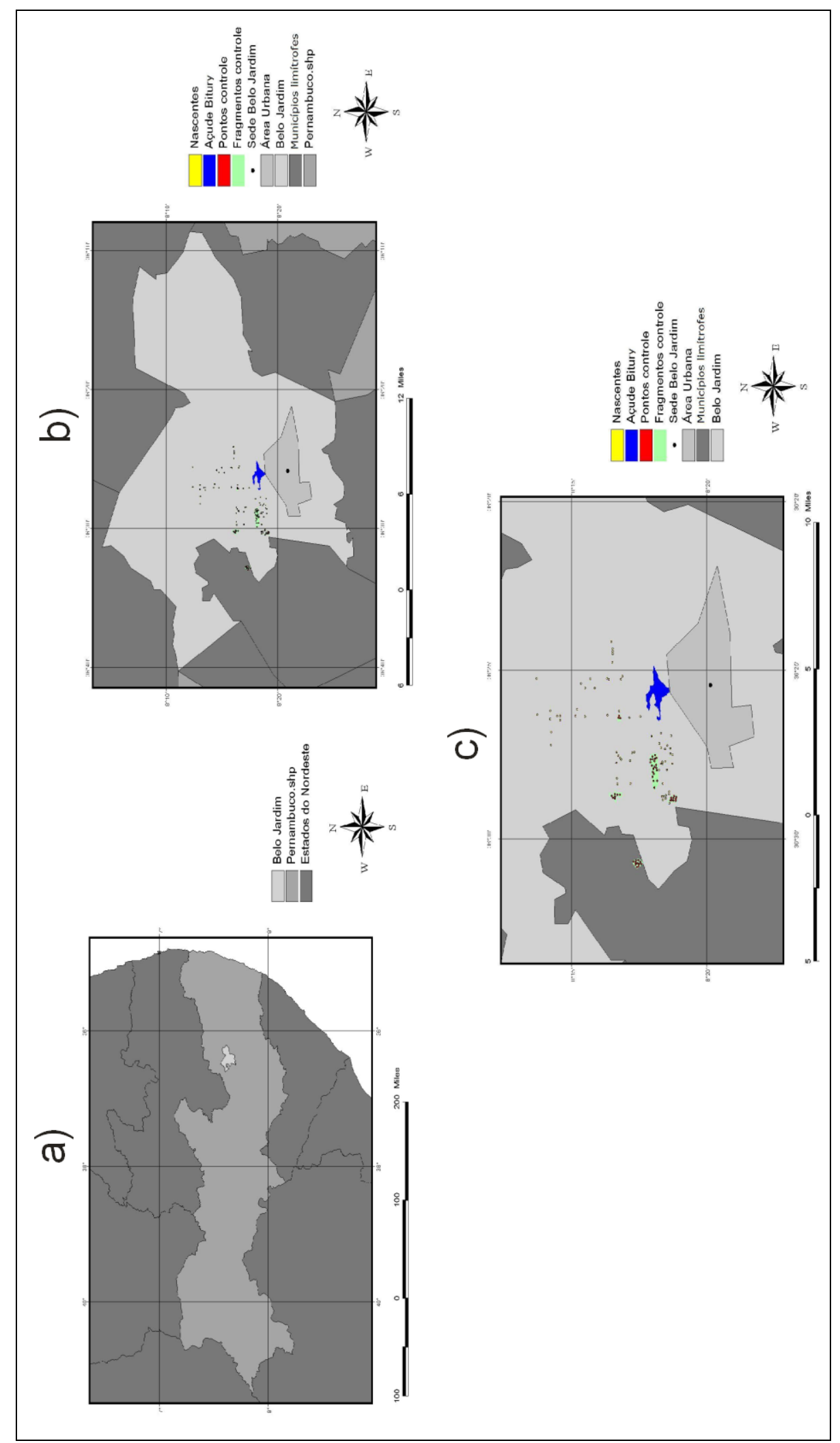

Figura 1. a) Localização do Estado de Pernambuco com os estados limítrofes, destacando o Município de Belo Jardim; b) Município de Belo Jardim, destacando a área urbana com a sede e área da microbacia com o açude; c) recorte destacando a microbacia com o açude, os 50 pontos controle e as 66 nascentes, a área urbana e a sede. 


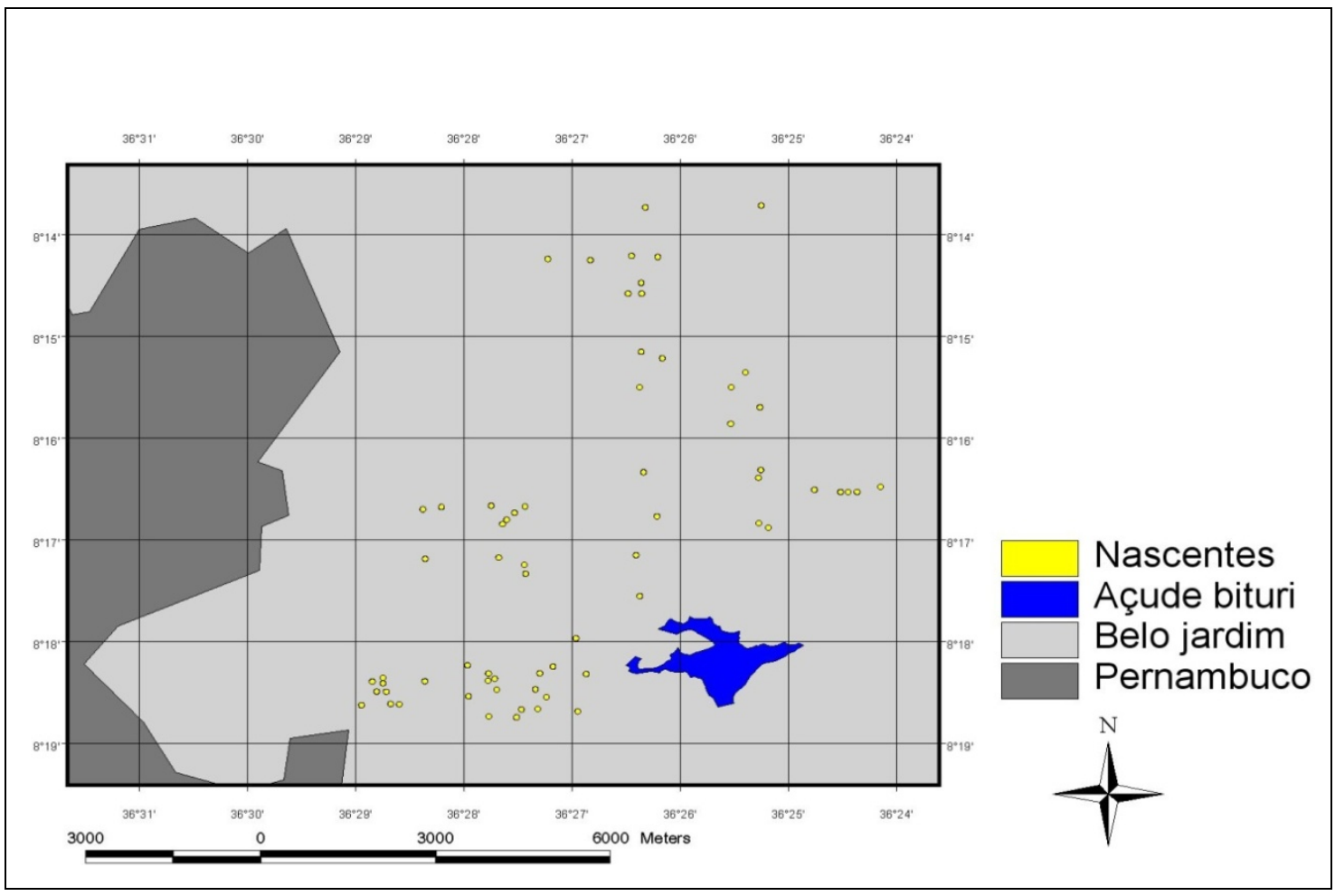

Figura 2. Representação da área da microbacia do Bitury, compreendendo os pontos das 66 nascentes, destacando o Açude Bitury.

Utilizou-se as imagens do satélite LANDSAT $5^{\mathrm{TM}}$, nas bandas 3 (vermelho visível) e 4 (infravermelho próximo), na data de 29/09/2010.A Figura 3 corresponde a imagem da banda 3 e a Figura 4 a imagem da banda 4, na data de 29/09/2010.

Após serem geoprocessadas no ArcGIS 9.2, as imagens foram usadas para estimar as densidades de vegetação da diferença normalizada NDVI, que na Figura 5 aparecem na amostragem de algumas nascentes, na forma de "pixel”, que é uma área mínima correspondente a cada ponto obtido pelos sensores do satélite. Nas imagens NDVI, os níveis de cinza mais claro expressam valores que representam altos índices de vegetação, enquanto os níveis de cinza mais escuro representam baixos índices de vegetação com níveis próximo a zero. Estes valores baixos correspondem a alvos urbanos como área construída, solo exposto e água (Rosemback et al., 2004).

Foram definidas 50 áreas controle nos fragmentos florestais da área da microbacia, utilizando-se o mesmo critério de distância para a seleção das 66 nascentes (Figura 6), com suas coordenadas geográficas determinadas utilizando-se um aparelho de GPS (Garmim, Colorado 300). Foi usado o programa ArcGis 9.2 para criar as áreas em torno, tanto nas áreas controle como nas nascentes, conforme a determinação do CONAMA (Conselho Nacional do Meio Ambiente) e o Código Florestal que estabelecem limites para a área de vegetação que margeiam os diversos corpos de água.

\section{Uso das nascentes}

O Sistema de Informações da Atenção Básica, do Ministério da Saúde, através da Secretaria de Saúde do município faz o levantamento da situação de domicílios coletando os dados junto à população no local de moradia. De acordo com esse sistema, a população residente na área da microbacia está dividida em 10 agrupamentos de localidades "principais", que inclui as localidades menores situadas nas proximidades, cuja área de abrangência está definida para atuação dos agentes 


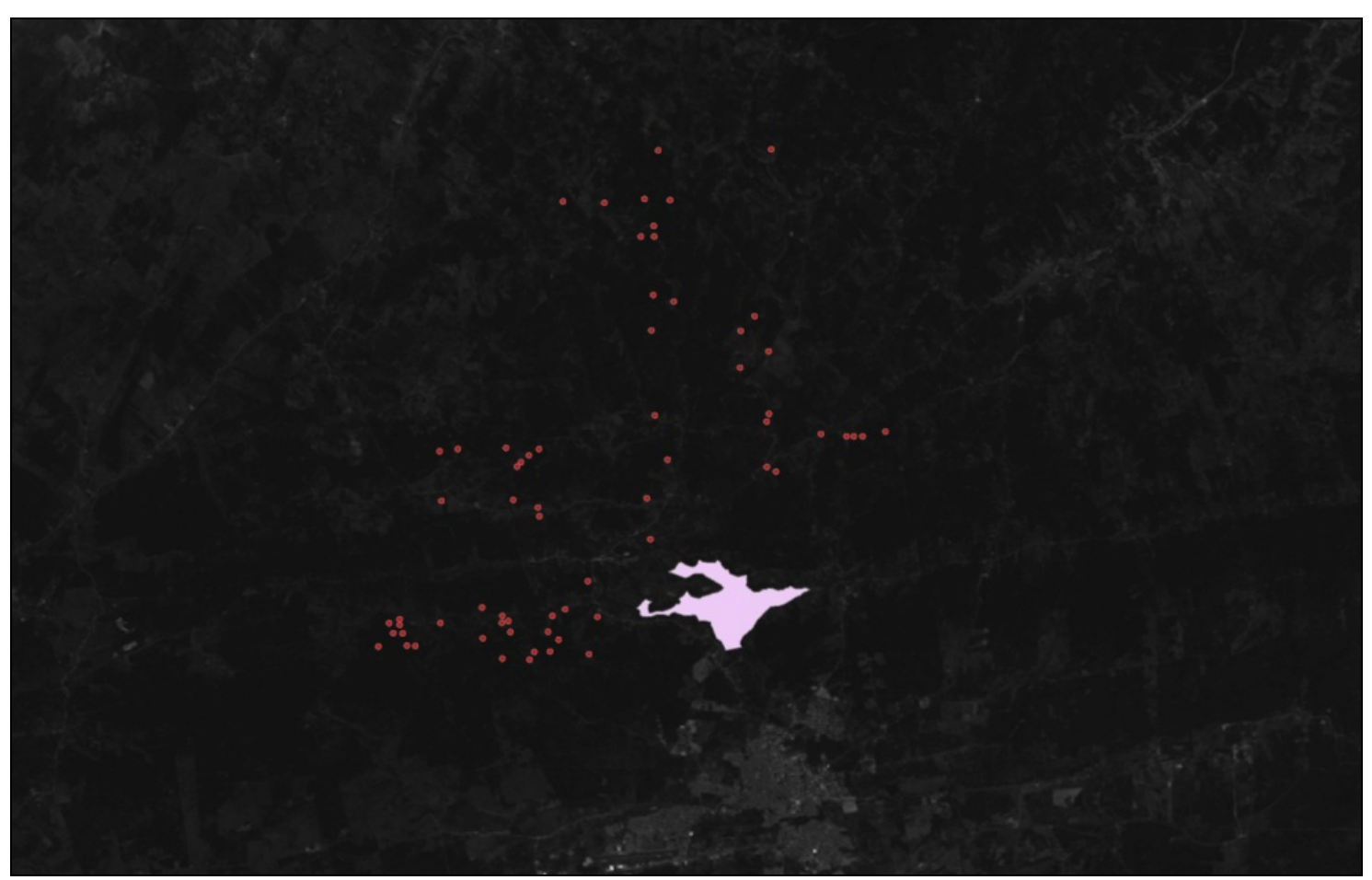

Figura 3. Recorte da imagem da Banda 3 do Satélite LANDSAT $5^{\mathrm{TM}}$, correspondendo ao vermelho visível,com baixa reflectância, aparecendo em tons de cinza escuro, destacando os pontos das 66 nascentes e o polígono do Açude Bitury.

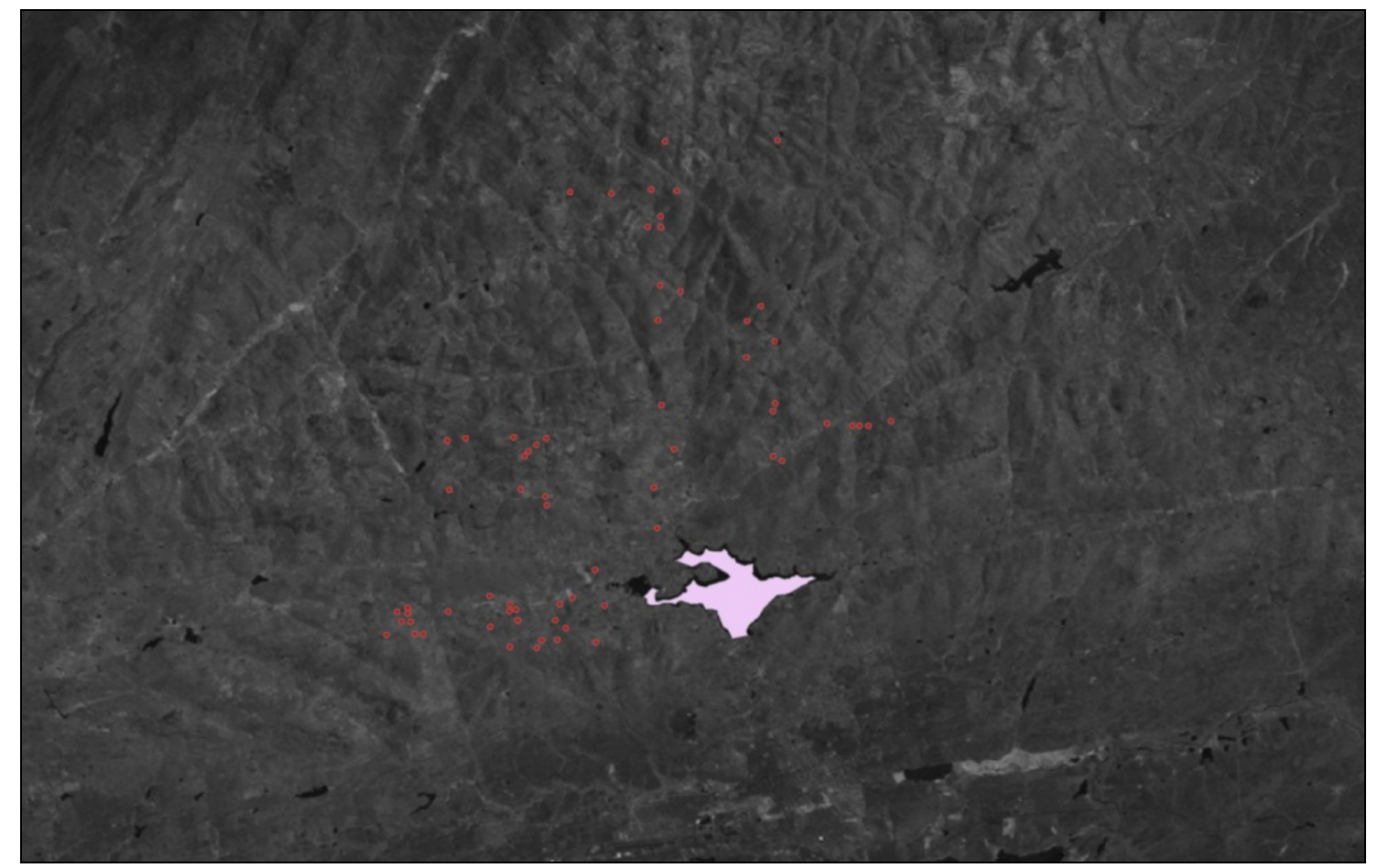

Figura 4. Recorte da imagem da Banda 4 do Satélite LANDSAT $5^{\mathrm{TM}}$ correspondendo ao infravermelho próximo, com alta reflectância, aparecendo em tons de cinza claro, destacando os pontos das 66 nascentes e o polígono do Açude Bitury. 


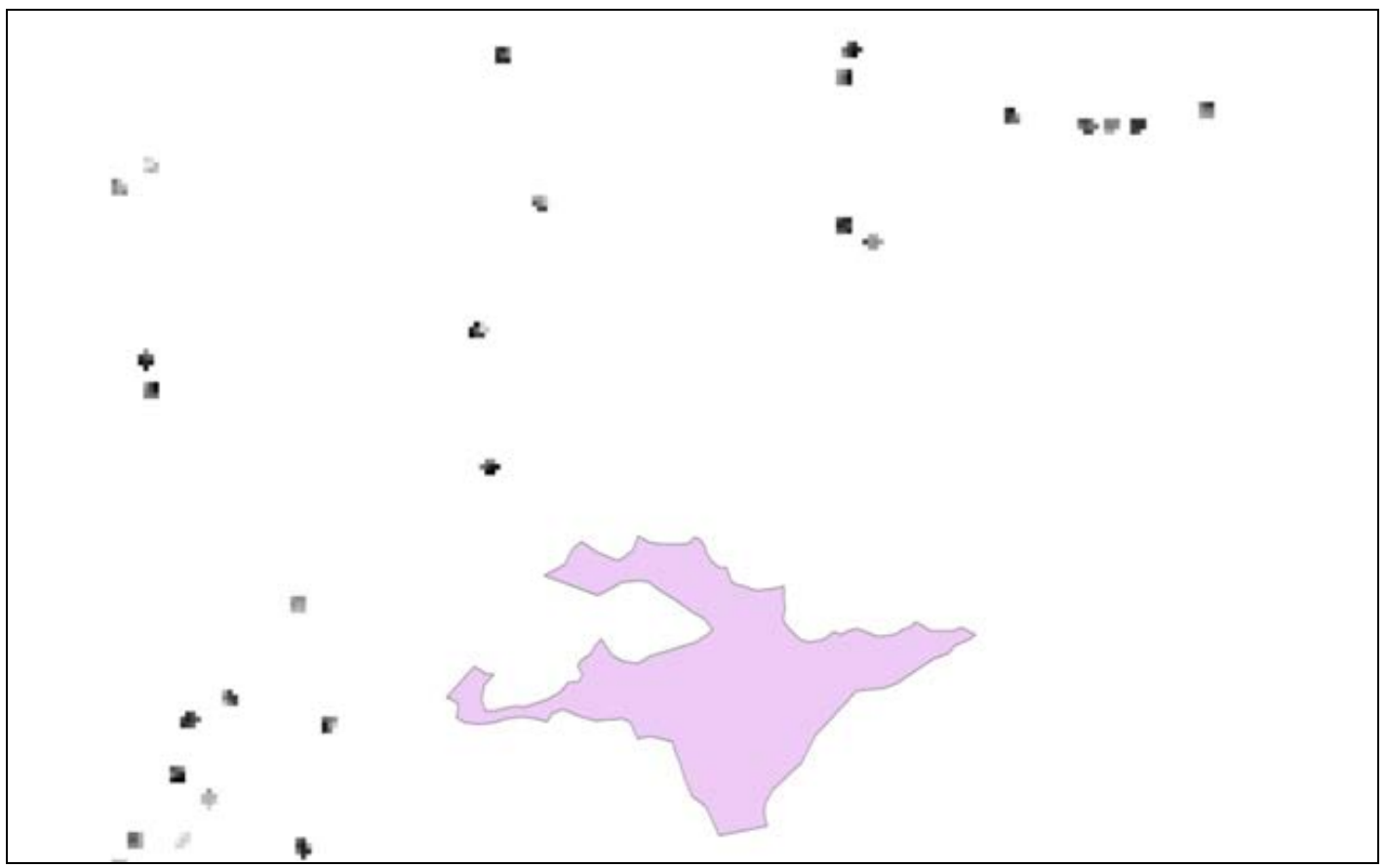

Figura 5. Recorte da imagem de satélite da microbacia apresentando o NDVI (pontos escuros) de parte das nascentes, na forma em que aparece como resultado da reflectância do vermelho visível (Banda 3, cinza escuro) e infravermelho próximo (Banda 4, cinza claro) e a representação poligonal do Açude Bitury.

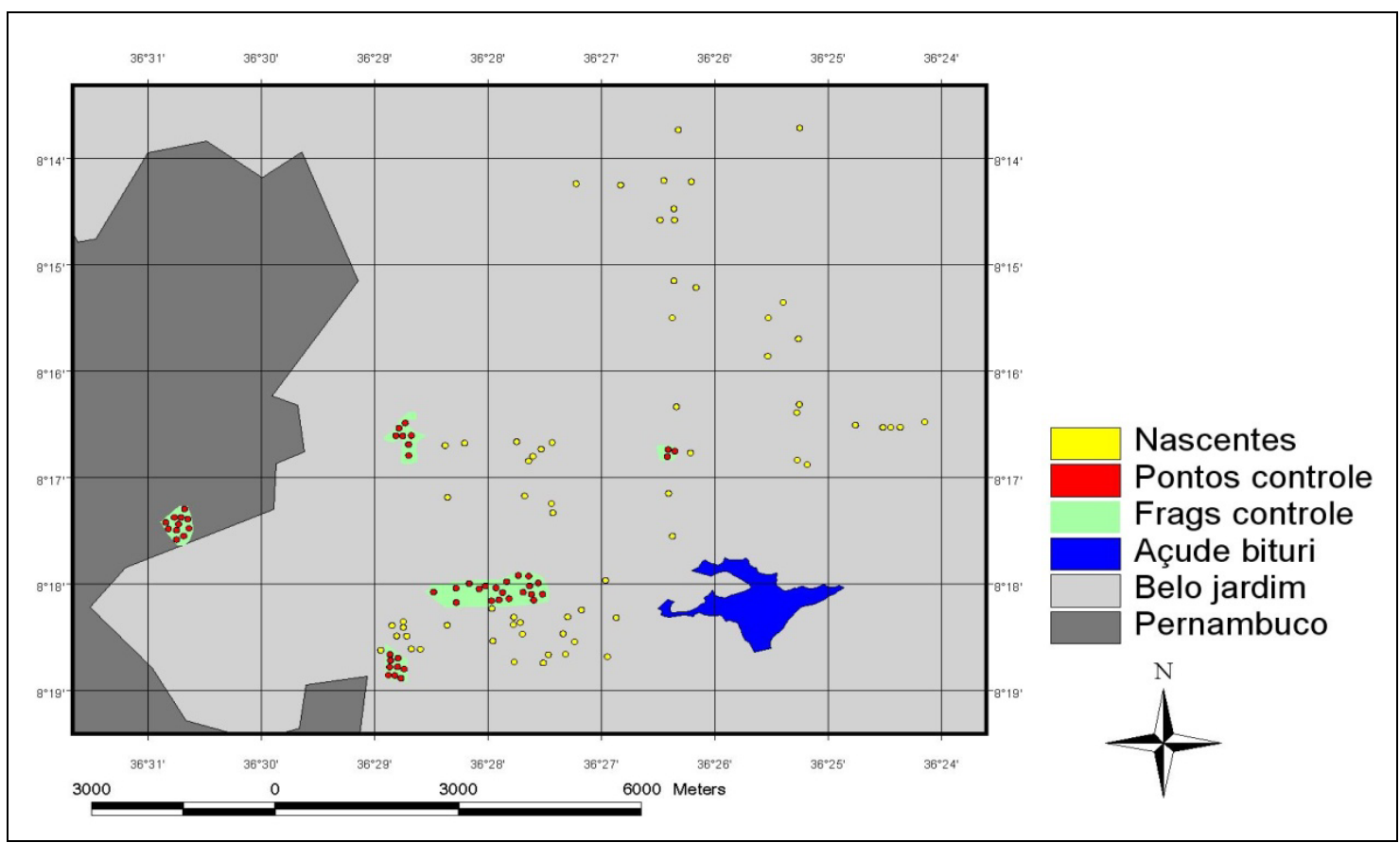

Figura 6. Localização dos pontos controle nas áreas de fragmentos e das 66 nascentes distribuídas ao longo da microbacia, destacando-se o Açude Bitury. 
comunitários de saúde. A partir dos dados coletados e registrados nas planilhas do SIAB, com as coletas iniciadas no ano de 2005, observou-se que o uso da água retirada diretamente das nascentes para abastecimento doméstico pela população residente na área da microbacia é um procedimento usual na maioria absoluta dos domicílios. Foi testada a hipótese de que existe correlação negativa entre o uso das nascentes e a qualidade da vegetação no seu entorno.

\section{Análises \\ Todas as hipóteses deste trabalho foram testadas com o uso de Modelos Lineares Generalizados (GLM).}

\section{Resultados e discussão}

Ao se comparar as imagens de NDVI das áreas em torno das nascentes e dos pontos controle, pode-se perceber que os valores de índice de vegetação apresentados por este último são maiores em relação ao primeiro, conforme demonstrado no gráfico da Figura 7, o que corrobora o resultado esperado de maior vigor da vegetação nas áreas não degradadas. $\mathrm{O}$ NDVI médio das nascentes $(0,57 \pm 0,082$; média \pm DP; Figura 8) foi significativamente $\left(\mathrm{F}_{1 / 982}=189,91 ; \mathrm{p}<0,001\right)$ menor do que o NDVI médio das áreas controle (063 \pm 0,036; média \pm DP $)$.

Na Tabela 1 observa-se o resultado estatístico dos valores numéricos do índice de vegetação NDVI das 66 nascentes estudadas.

As nascentes avaliadas estão distribuídas entre as localidades de acordo com o critério de seleção que foi utilizado para este estudo. Também foi calculado o índice de vegetação usando o NDVI nas 10 localidades de referência para o SIAB na área de abrangência da microbacia como pode ser observado no gráfico da Figura 9, com os resultados das médias em valores numéricos. A análise estatística apresentada na Tabela 2 mostra que é significativa a diferença entre as médias.

Nas bacias com cobertura de vegetação natural, esta promove a proteção contra a erosão do solo, a sedimentação e a lixiviação excessiva de nutrientes (Sopper, 1975), sendo essas áreas muito importantes para manter o abastecimento de água de boa qualidade. Por outro lado, as práticas que tem lugar após a retirada das árvores tendem a produzir intensa e prolongada degradação da qualidade da água (Brown, 1988).

O Código Florestal Brasileiro, Lei $\mathrm{n}^{\circ}$ 4.771/1965 (Brasil, 1965), em seu artigo $2^{\circ}$, estabelece as faixas marginais ao longo dos rios e córregos, conforme sua largura. A Resolução do CONAMA n ${ }^{\circ}$ 303/2002 (Brasil, 2002), que dispõe sobre parâmetros, definições e limites das Áreas de Preservação Permanente (APP), em seu art. $2^{\circ}$, enfatiza curso d'água e nascentes perenes ou intermitentes com área vegetada de $50 \mathrm{~m}$ de raio.

As áreas de preservação permanente (APP) são regiões nas quais, por imposição da lei, a vegetação deve ser mantida intacta, tendo em vista garantir a preservação dos recursos hídricos, da estabilidade geológica, da biodiversidade, do fluxo gênico de fauna e flora, bem como do bem-estar da população humana. A legislação Federal transformou as APP em santuários reservados ao desenvolvimento da biodiversidade, sendo áreas intocáveis às atividades antrópicas.

Considerando esses aspectos, constatou-se, em toda a microbacia, a existência de nascentes e córregos sem atender os dispositivos legais no que se refere à cobertura vegetal. Ou seja, foi observado nos resultados de NDVI de que o estado de conservação das nascentes é significativamente pior do que era esperado, mesmo que em alguns casos as nascentes possam apresentar certo grau de cobertura vegetal, indicando assim, a existência de um processo antrópico de degradação numa área de preservação permanente, com possíveis repercussões na disponibilidade e qualidade hídrica na região.

Os testes realizados para a hipótese de que existe correlação entre a qualidade das nascentes e as distâncias que estas apresentam em relação ao Açude Bitury e à sede do município, mostraram não haver significância. Portanto, a qualidade das nascentes não sofre alteração quando é 


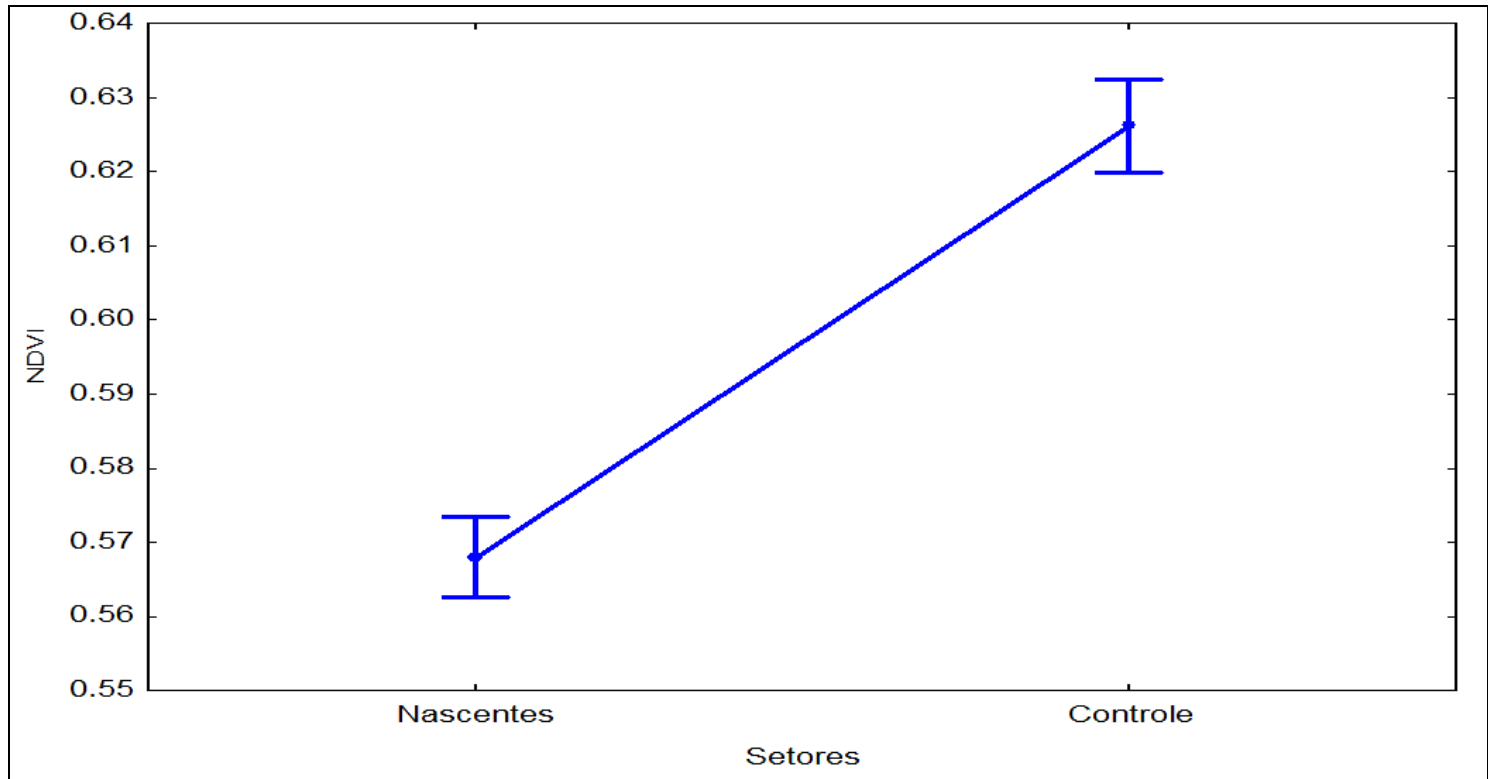

Figura 7. Média de NDVI das nascentes da microbacia do Bitury e das áreas controle (florestas preservadas da região).

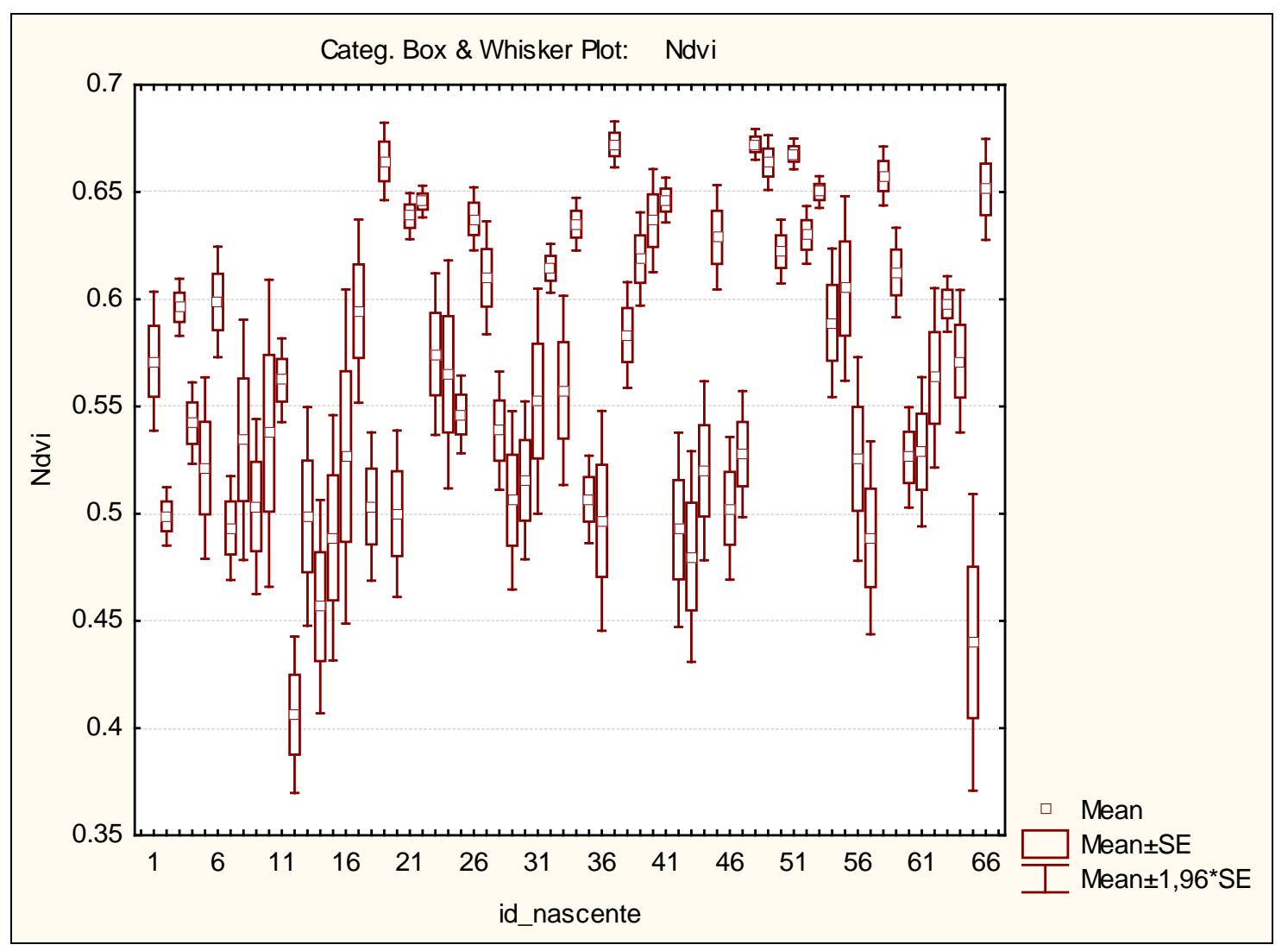

Figura 8. Média e Desvio Padrão de NDVI em torno das 66 nascentes estudadas, evidenciando a variação de estados de conservação. 
Tabela 1. Análise estatística dos valores médios de NDVI de 66 nascentes da Microbacia do Rio Bitury.

\begin{tabular}{lrrrrr}
\hline & G. L. & \multicolumn{1}{c}{ SS } & \multicolumn{1}{c}{ MS } & \multicolumn{1}{c}{ F } & \multicolumn{1}{c}{ P } \\
\hline Intercepto & 1 & 180,6584 & 180,6584 & 48505,04 & 0,00 \\
ID. Nascente & 65 & 1,6410 & 0,0252 & 6,78 & 0,00 \\
Erro & 494 & 1,8399 & 0,0037 & & - \\
\hline Total & $\mathbf{5 5 9}$ & $\mathbf{3 , 4 8 0 9}$ & - & - & - \\
\hline
\end{tabular}

G.L. = Grau de liberdade; SS = Soma dos quadrados; MS = Quadrado médio; F = distribuição estatística F; $\mathrm{P}=. \mathrm{p}$-valor probabilidade de significância.

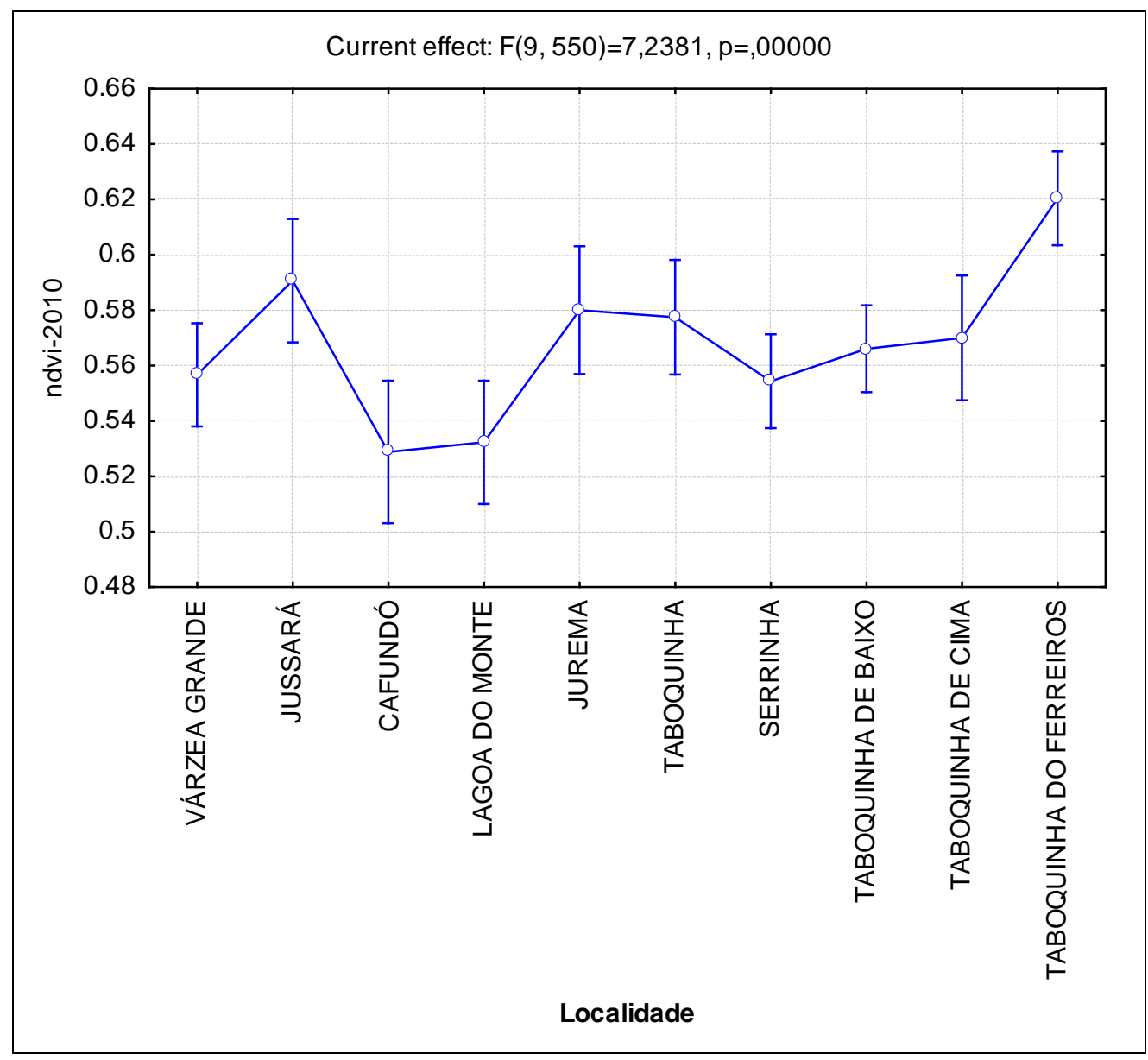

Figura 9. Representação gráfica das médias de NDVI, em valores numéricos, de cada localidade da área da microbacia, usada como referência pela Secretaria de Saúde de Belo Jardim no Sistema de Informação da Atenção Básica (SIAB).

Tabela 2. Análise estatística entre os índices NDVI calculados para cada uma das 10 localidades de referência no levantamento da situação de domicílios na área da microbacia do Bitury.

\begin{tabular}{lcccrc}
\hline & G.L. & SS & MS & \multicolumn{1}{c}{ F } & P \\
\hline Intercepto & 1 & 164,0457 & 164,0457 & 28990,31 & 0,000000 \\
Localidade & 9 & 0,3686 & 0,0410 & 7,24 & 0,000000 \\
Erro & 550 & 3,1123 & 0,0057 & & \\
\hline Total & $\mathbf{5 5 9}$ & $\mathbf{3 , 4 8 0 9}$ & & &
\end{tabular}

G.L. = Grau de liberdade; SS = Soma dos quadrados; MS = Quadrado médio; F = distribuição estatística F; $\mathrm{P}=$.p-valor probabilidade de significância. 
considerado o fator distância em relação aos pontos que foram determinados. Ou seja, a população não usa ou destrói mais nascentes próximas do que distantes da sede do município ou do açude principal.

Por outro lado, nos dados colhidos junto a Secretaria de Saúde de Belo Jardim, sobre a Situação de Domicílios, tem-se um total de 799 moradias distribuídas nas 10 localidades de referência, abrangendo a área de localização das nascentes, das quais, 521 moradias ou $65,3 \%$ fazem uso das nascentes retirando água para consumo doméstico (Tabela 3). Foi observado que existe uma correlação negativa significativa entre o uso das nascentes pela população e o NDVI da cobertura vegetal no entorno, conforme demonstrado na Tabela 4.

Tabela 3. Localidades de referência nas fichas do SIAB com o número de domicílios que usam nascentes ou poços no seu entorno.

\begin{tabular}{lccc}
\hline Localidade & $\begin{array}{c}\mathbf{N}^{\mathbf{0}} \text { de } \\
\text { domicílios }\end{array}$ & $\begin{array}{c}\text { Usam } \\
\text { nasc/poço }\end{array}$ & $\begin{array}{c}\text { \% domicílios usam } \\
\text { nasc/poço }\end{array}$ \\
\hline Taboquinha dos Ferreiros & 27 & 19 & 72,6 \\
Lagoa do Monte & 51 & 46 & 91,7 \\
Serrinha & 100 & 93 & 93,0 \\
Cafundó & 72 & 64 & 89,5 \\
Jurema & 78 & 43 & 55,7 \\
Taboquinha de Baixo & 141 & 81 & 57,6 \\
Taboquinha (Patos) & 77 & 32 & 41,2 \\
Taboquinha de Cima & 154 & 73 & 47,4 \\
Jussará & 60 & 45 & 74,3 \\
Várzea Grande & 39 & 25 & 64,1 \\
\hline
\end{tabular}

Tabela 4. Correlação entre o uso das nascentes e o índice de NDVI da vegetação do entorno.

\begin{tabular}{lrrrrr}
\hline & SS & G.L. & \multicolumn{1}{c}{ MS } & \multicolumn{1}{c}{ F } & \multicolumn{1}{c}{ P } \\
\hline Intercepto & 39,67169 & 1 & 39,67169 & 6417,651 & 0,000000 \\
Uso & 0,03151 & 1 & 0,03151 & 5,097 & 0,024353 \\
Erro & 3,44936 & 558 & 0,00618 & & \\
\hline
\end{tabular}

G.L. = Grau de liberdade; SS = Soma dos quadrados; MS = Quadrado médio; F = distribuição estatística F; $\mathrm{P}=$.p-valor probabilidade de significância.

Analisando-se os dados da situação de domicílios observa-se que elevado número de famílias faz uso da água retirada diretamente das nascentes ou dos poços no seu entorno, o que implica na sua utilização para abastecimento sem procedimentos de análise e/ou processo de tratamento, tornando-se um meio propício para veiculação de infecções que tem a água como veículo de transmissão. A diarreia, por exemplo, faz parte do conjunto de infecções classificadas como de transmissão hídrica (Cairncross e Feachem, 1990).

\section{Conclusão}

Pode-se observar que, pelas características físicas da área estudada, esta é ambientalmente frágil e, diante dos diversos usos e ocupação do solo identificados, sobretudo com a forte pressão antrópica, constata-se que a Microbacia Hidrográfica do Rio Bitury vem sofrendo um processo de degradação acentuado.

As técnicas de geoprocessamento e sensoriamento remoto constituem uma imprescindível contribuição para o 
levantamento e monitoramento dos aspectos ambientais. As ferramentas disponibilizadas por essa área do conhecimento auxiliam tanto no gerenciamento de estudos da dinâmica da paisagem, quanto nas ações de fiscalização e até mesmo de conscientização ambiental.

Os baixos valores do NDVI no entorno das nascentes estão associados a atividades antrópicas e provavelmente a diminuição de cobertura vegetal.

A ação antrópica contribui de maneira relevante para o avanço da degradação da vegetação ciliar, comprometendo principalmente, a estrutura das nascentes, que por estarem sem cobertura estão sujeitas ao desaparecimento.

O monitoramento da região da microbacia torna-se necessário, por ser um indicador da qualidade ambiental quando em atendimento aos pressupostos legais e por disponibilizar informações que indicam decisões a serem tomadas quanto à prevenção ou recuperação do meio ambiente com influência significativa sobre a saúde da população.

\section{Declaração de conflito de interesses}

Os autores declaram não haver
conflitos de interesses.

\section{Referências}

Almeida, D. S.; Duarte, A. J.; Araújo, R. P. Projeto de recuperação de matas ciliares e nascentes da Bacia do Rio dos Mangues. Anais do VI Congresso e Exposição Internacional Sobre Florestas, Porto Seguro, p. 575-576, 2000.

Arcova, F. C. S.; Cicco, V. Características do deflúvio de duas microbacias hidrográficas no laboratório de hidrologia florestal Walter Emmench, Cunha-SP. Revista do Instituto Florestal de São Paulo, v. 9, n. 2, p. 153-170, 1997.

Arcova, F. C. S.; Cesar, S. F.; Cicco, V. Qualidade da água em microbacias recobertas por floresta de Mata Atlântica, Cunha, São Paulo. Revista do Instituto Florestal de São Paulo, v. 10, n. 2, p. 185-196, 1998.

Arcova, F. C. S.; Cicco, V. Qualidade da água de microbacias com diferentes usos do solo na região de Cunha, Estado de São Paulo. Scientia Florestalis, v. 5, n. 6, p. 125-134, 1999.

Assad, M. L. L. Sistemas de Informações Geográficas na avaliação da aptidão agrícola de terras. In: Assad, E. D.; Sano, E. E. (Ed). Sistema de Informações Geográficas: aplicações na agricultura. Planaltina: EMBRAPA/CPAC, 1998.

Brasil. Leis, decretos etc. Decreto $\mathbf{n}^{0}$ 23.793, de 23 de janeiro de 1934. Approva o codigo florestal que com este baixa. Disponível em: <http://www.planalto.gov.br/ccivil_03/decreto/ 1930-1949/D23793impressao.htm>. Acesso em: 04 abr. 2015.

Brasil. Leis, decretos etc. Decreto no 24.643, de 10 de julho de 1934. Decreta o Código de Águas. Disponível em: <http://www.planalto.gov.br/ccivil_03/decreto/ D24643compilado.htm>. Acesso em: 04 abr. 2015.

Brasil. Leis, decretos etc. Lei $\mathbf{n}^{\mathbf{0}}$ 4.771, 15 de setembro de 1965. Institui o novo Código Florestal. Disponível em: $<$ http://www.planalto.gov.br/ccivil_03/

LEIS/L4771impressao.htm>. Acesso em: 04 abr. 2015.

Brasil. Leis, decretos etc. Resolução CONAMA no 20, de 18 de junho de 1986. Disponível em: <http://www.mma.gov.br/port/ conama/res/res86/res2086.html>. Acesso em: 04 abr. 2015.

Brasil. Leis, decretos etc. Lei $\mathbf{n}^{\mathbf{0}} \mathbf{9 . 4 3 3}$, de 8 de janeiro de 1997. Institui a Política Nacional de Recursos Hídricos, cria o Sistema Nacional de Gerenciamento de Recursos Hídricos, regulamenta o inciso XIX do art. 21 da Constituição Federal, e altera o art. $1^{\circ}$ da Lei 8001, 13/03/1990, que modificou a Lei n. 7.990, 28/12/1989. Disponível em: <http://www.planalto.gov.br/ccivil_03/LEIS/ L9433.htm>. Acesso em: 04 abr. 2015.

Brasil. Leis, decretos etc. Resolução CONAMA n' 303 , de 20 de março de 2002. Dispõe sobre parâmetros, definições e limites de Áreas de Preservação Permanente. Disponível em: <http://www.mma.gov.br/port/conama/ legiabre.cfm?codlegi=299>. Acesso em: 04 abr. 2015.

Brasil. Leis, decretos etc. Resolução CONAMA no 357, de 17 de março de 2005. Dispõe sobre a classificação dos corpos de água e diretrizes ambientais para o seu enquadramento, bem como estabelece as condições e padrões de lançamento de efluentes, e dá outras providências. Disponível em: 
<http://www.mma.gov.br/port/conama/res/res05 /res35705.pdf>. Acesso em: 04 abr. 2015.

Brasil. Leis, decretos. Lei $\mathbf{n}^{0}$ 12.651, de 25 de maio de 2012. Dispõe sobre a proteção da vegetação nativa; altera as Leis $n^{\text {os }} 6.938$, de 31 de agosto de 1981, 9.393, de 19 de dezembro de 1996, e 11.428, de 22 de dezembro de 2006; revoga as Leis $\mathrm{n}^{\text {os }} 4.771$, de 15 de setembro de 1965, e 7.754, de 14 de abril de 1989, e a Medida Provisória ${ }^{\circ}$ 2.166-67, de 24 de agosto de 2001; e dá outras providências. Disponível em: <http://www.planalto.gov.br/ ccivil_03/_ato2011-2014/2012/lei/

L12651compilado.htm>. Acesso em: 04 abr. 2015.

Brown, G. W. Forestry and water quality. Oregon: 1988.

Cairncross, S.; Feachem, R. G. Environmental health engineering in the tropics: an introductory text. 2. ed. Chichester: John Wiley \& Sons, 1990.

Castro, P. S.; Gomes, M. A. Técnicas de conservação de nascentes. Ação Ambiental. Viçosa: Editora da UFV, 2001. p. 24-26,

Donadio, N. M. M.; Galbiatti, J. A.; Paula, R. C. Qualidade da água de nascentes com diferentes usos do solo na Bacia Hidrográfica do Córrego Rico, São Paulo, Brasil. Eng. Agríc., v. 25, n. 1, 2005.

Hermani, L. C. Mananciais estão comprometidos. O Estado de São Paulo, São Paulo, 13 jan., 1997. Ambiente. p. 11.

Hidalgo, P. <b> Diagnóstico socioeconômi$\mathrm{co}</ \mathrm{b}>$. João Pessoa: PRM/METROPLAN/ AGP, 1992. (Curso Sobre Manejo Conservacionista de Bacias Hidrográficas).

ITEP/LAMEPE - Instituto de Tecnologia de Pernambuco/Laboratório de Meteorologia de Pernambuco. Dados pluviométricos. Banco de Dados Pluviométrico. Recife: ITEP/LAMEPE, 2011.

Lillesand, T. M.; Kiefer, R. W. Remote sensing and image interpretation. 3. ed. New York: John Wiley \& Sons, 1994.

Lima, W. P. Hidrologia florestal aplicada ao manejo de bacias hidrográficas. Piracicaba: Universidade de São Paulo, Escola Superior de Agricultura “Luiz de Queiroz”, 2008.

Loch, R. E. N.; Kirchiner, F. F. Classificação de imagens multiespectrais Landsat ${ }^{\mathrm{TM}}$ e feições de textura: mapeamento da cobertura vegetal. Revista Floresta, v. 27, n. 1/2, p. 41-58, 2000.

Mckee, J. E.; Wolf, H. W. Water quality criteria. California: California State Water
Resources Control, 1971. (Board Publication, 3-A).

Natal, D.; Menezes, R. M. T.; Mucci, J. L. N. Fundamentos de Ecologia Humana. In: Philippi Jr., A. (Ed.). Saneamento, saúde e ambiente. Barueri: Manole, 2005.

Oliveira-Filho, A. T.; Almeida, R. J.; Mello, J. M.; Gavilanes, M. L. Estrutura fitossociológica e variáveis ambientais em um trecho de mata ciliar do Córrego Vilas Boas, Reserva Biológica do Poço Bonito, Lavras (MG). Revista Brasileira de Botânica, v. 17, n. 1, p. 67-85, 1994.

Philippi Jr., A.; Silveira, V.F. Controle da qualidade das águas. In: Philippi Jr., A. (Ed.). Saneamento, saúde e ambiente. Barueri: Manole, 2005.

Pineda, M. D.; Schafer, A. Adequação de critérios e métodos de avaliação da qualidade de águas superficiais baseada no estudo ecológico do Rio Gravataí, Rio Grande do Sul, Brasil. Ciência e Cultura, v. 39, n. 2, p. 198-206, 1987.

Primavesi, O.; Freitas, A. R.; Primavesi, A. C.; Oliveira, H. T. Water quality of Canchim's creek watershed in São Paulo, SP, Brazil, occupied by beef and dairy cattle activities. Brazilian Archives of Biology and Technology, v. 45, n. 2, p. 209-217, 2002.

Queiroz, J. T. M. A água de consumo humano distribuída à população e a ocorrência de diarréia: um estudo ecológico no município de Vitória-ES. Belo Horizonte: Universidade Federal de Minas Gerais, 2006. (Dissertação de Mestrado).

Reis, T. E. S.; Barros, O. N. F.; Reis, L. C. Uso de SIG e geoestatística no estudo da dependência espacial e estabelecimento de superfície de correlação de fragmentos florestais em áreas de baixa aptidão agrícola. Anais da IV Mostra do Talento Científico, São Paulo, 2004.

Rosemback, R.; Silva França, A. M.; Florenzano, T. G. Análise comparativa dos dados NDVI obtidos de imagens CCD/CBERS-2 e TM/LANDSAT-5 em área urbana. São Paulo: INPE, 2004.

Secretaria de Saúde de Belo Jardim. Semana Epidemiológica 2009 e 2010.

Secretaria de Saúde de Belo Jardim. Situação de Moradia e Saneamento do Município de Belo Jardim/SIAB 2005 a 2010.

SECTMA - Secretaria de Ciência Tecnologia e Meio Ambiente/PE. Projeto para recuperação e conservação ambiental da Bacia Hidrográfica do Rio Ipojuca. Recife: 
SECTMA, 2004. (Programa Nacional do Meio Ambiente - PNMA II).

Shimabukuro, E. Y.; Batista, E. T.; Mello, M. K.; Moreira, J. C.; Duarte, Y. Using shade fraction image segmentation to evaluate deflorestation in Landsat Thematic Mapper images of Amazonian Region. International Journal Remote Sensing, v. 19, n. 3, p. 535541, 1998.

Setti, A. A. A necessidade do uso sustentável dos recursos hídricos. Brasília: IBAMA, 1994.

SRHE/PE - Secretaria de Recursos Hídricos e Energéticos/PE. Plano Hidroambiental das Bacias Hidrográficas dos Rios Capibaribe e Ipojuca. Recife: SRHE, 2010.

Souza, A. D. G.; Tundisi, J. G. Hidrogeochemical comparative study of the Jaú and Jacaré-Guaçu River Watersheds, São Paulo,
Brazil. Revista Brasileira de Biologia, v. 60, n. 4, p. 563-570, 2000.

Souza, E. R.; Fernandes, M. R.; Neves, J. C. Proteção de nascentes. Belo Horizonte: Emater-MG, 2006. (Série Ambiente).

Susser, M. The logic in Ecological: I. The logic of analysis the logic of design. American Journal of Public Health, v. 84, n. 5, p. 825829, $1994 . \quad$ Disponível em: <http://www.ncbi.nlm.nih.gov/pmc/articles/ PMC1615050/pdf/amjph00456-0123.pdf>. Acesso em: 04 abr. 2015.

Xavier, A. L.; Teixeira, D. A. Diagnóstico das nascentes da Sub-Bacia Hidrográfica do Rio São João em Itaúna, MG. Anais do VIII Congresso de Ecologia do Brasil, Caxambu, p 1-2, 2007. 